\title{
What are the Problems for Students in Writing The First Research Paper in a Second Language?
}

\author{
Muhammad Javed \\ M.A. English Literature \\ Government College University Faisalabad \\ Pakistan \\ dj211rb@gmail.com
}

\begin{abstract}
In this paper, I have mentioned the problems faced by students in writing the first research paper and solution of these problems. There are a lot of students who have the ability to write the research paper, but due to the lack of guidance and not familiar with the format and the process of writing a research paper, they are unable to write this type of academic work. So I have mentioned in this study the different types of problems and their solution. In this paper, I deal with lots of problems but major problems are eight. The first thing I deal in this study is the problem in selecting the research topic, what type of topic can be selected at the student level? And how can choose a topic? Secondly, how to write the introduction? And problems in writing the introduction. Thirdly, problems in writing the literature review and rules of writing the literature review, fourthly the format of a research paper. Second language problem which is a major problem in writing a research paper; students are much worried to face this problem. The fifty percent students of second language having problems in writing the research papers. I have mentioned the problem of plagiarism, paraphrase and the starting
\end{abstract}


point of a research paper. I have collected the data from universities. I have organized two tests in order to collect the data. This study will be very helpful for the beginner researchers.

Keywords: Topic for Research, First Paper, Paraphrase, Second Language, Literature Review, Plagiarism, Format and Guidance.

\section{Introduction}

In this paper, I deal with those problems which are faced by student in wringing their first research paper. I deal with different types of problems in process and format. Firstly, I deal with the problem in selecting the research topic, what type of topic can be selected at the student level? And how can choose the topic? And the solution to the problems which are faced in choosing the topic? Secondly, I deal with how to write the introduction? And problems in writing the introduction and their effective solution for Introduction of a research paper, students do not know what things can be added in the Introduction section. There are the main three things to be discussed in your Introduction section of the research paper. And thirdly I deal how to write a literature review? Problems in writing the literature review and rules of writing the literature review. Fourthly, I deal with the format of research paper and guideline problems in writing a research paper. Fifthly, I deal with the second language problem, which is a major problem in writing a research paper; students are much worried to take this problem. The fifty percent students of second language having problems in writing research papers. This type of problem has not a magic role to solve it, but I deal with this problem. Sixthly, I deal with the Plagiarism, the students who are writing their research paper often raise questions about plagiarism, how many words we need to change in a sentence to avoid the plagiarism, the answer is that there are no great words or phrases to add in a sentence to make the idea of your own, and real-word needs real opinions. I deal with 
different type of mistakes which are very common in students. Seventhly, I deal with paraphrase as we all know that most of the students often raise the questions about the paraphrase the ideas of authors in order to avoid the plagiarism in their work which is a second major problem in students. Students often raise the questions about how much words we can change to avoid the plagiarism, another problem faced by students. Eighthly and the last thing I deal in this paper is the Starting point of a research paper as we know the format of the research paper, means, the things come in position-wise in this paper,

For instance

Here is a list of the things that will come from start to end; these are the positions of things that will be placed in a research paper:

1. Abstract

2. Keywords

3. Introduction

4. Literature Review

5. Methodology (Research questions or Hypothesis, Objective, Population, and Sampling)

6. Data analysis $\backslash$ Data collection

7. Finding

8. Discussion and Conclusion

9. References

10. Appendix

11. Future Work

Above is the main format of the research paper. We can see the position of Abstract as on the top, but we never start our research with the Abstract. We have a different way to start the research paper which has proper start and end; this is one of my major dealing in my 
research paper. There are the main three things to discuss in your introduction section of the research paper. Introduction of the research paper, students do not know what things can be added in the introduction section.

\section{Methodology}

In the methodology section, I deal with population and sample, research design, research questions and instrument used in data collection procedure.

\section{Research Design}

My research design is descriptive and it is problem-solving research. In this paper, I used a table to show the percentage of the problem.

Population and Sample

The population of my study is not only the graduate level students but the master level also who are writing the research paper in a second language and their first time. I took two hundred students as a sample from Govt. University and Punjab University.

\section{Research Instruments}

I took only two tests as an instrument to collect my data from Punjab University and second test in GC University Faisalabad. My test was in "Yes and No" form full with problems.

\section{Literature review}

It is the general view about the students and the criticism of the research assessors; it's hard to write good literature review for beginner researchers. Your literature review 
should have the ability to attract the readers, and there are some great contributions to your research paper on the topic. The main motive of the literature the review is not just the summary of what the authors currently knew about that topic, but it gives details, how it is right and reasonable and these are in the form of arguments. The research is being expected that I should be in a real combination of awareness for human. There are lots of brilliant students, who have the abilities to write, but, as we know in every aspect of life we need guidance to do some special things like a research paper. We can find a lot of things from the internet (YouTube) related to entertainment, sports, dramas and movies, but we cannot get credible material related to education and research activities, as we know there are lots of scholars in Pakistan and if they want, they can share their knowledge through any medium of the internet (YouTube) for our students, but in Pakistan mostly intelligent students who have the ability to write is not being guided.

The common mistakes in writing research paper: the literature review. Firstly, using personal opinions and emotions, you are actually working on the research paper and in the research paper you need to add the thoughts and ideas which already exist; you cannot add your own opinions and emotions. Secondly, when you are giving the reference of any author use only the last name and year of study, some of the students use the full name and full date; only use the last name and year of study which is mentioned in APA style. Some of the students use URLs, links in order to give the references of the author's studies which is not a good way, gives the complete details in the reference section not in the literature review; in literature review you can use only the last name and year of study of the author. Some of the students read a lot from other work, as a result; they add irrelevant data in their papers which is not related to his research topic and research questions. Another mistake of students to write the Abstract very first as his position in research paper which is one the major mistake in paper. 
Here are some other common mistakes,

Students don't dedicate their whole paper in the abstract because of lack of knowledge, if we take two lines from every section of the research paper, in this way we can wholly interpret the research paper, the condition is that you have to choose those two lines which qualify each section lucidly, and another mistakes are this. Sometimes a student gives the explanation in Abstract, which is not qualifying the subject. Hypotheses are not clearly show in the research paper.

Problems in Paraphrase

At the stage of graduation, it's time for the students to search out new things using their own abilities, especially in research writing (Colwell 2011). It is a great dare for those students who write a skillful research paper on the graduate level. This stage is to make a student developing their conceptual study. Mei-Ching Ho, 2013 mentioned that there are a lot of problems faced by graduate-level students in writing a research paper, including grammar, punctuation, data sources and they do not know how much explanation can be included in the research paper. Firstly, they do not have any clear idea that how to get relevant material (Literature Review) about that topic, after getting data very difficultly from different places, students do not have the knowledge about paraphrase, it is very helpful to get the ideas from the previous researcher's work and rewrite these ideas using their own wording to develop your research. Writing has two types of material; one is quotations and the second is paraphrase. The quotations are foremost things in your academic writing and students much use paraphrase in the papers, paraphrase takes a lot time but it will show either they understand the author's point of view or not. Yulia (2012) mentioned that he student who is a beginner in writing research the paper he needs to understand the paraphrase (how to write), otherwise, he will be in critical problems of Plagiarism, suppose you become a teacher and 
you are not known at all to paraphrase, you are an exemplar for you disciple, how to can motivate to your disciples? The paraphrase is the very masterly thing which is not found in every student. If we want to become a good researcher we need to become an expert in paraphrase otherwise, we will not become a good researcher because most students haven't ability to solve this problem easily, as we know that a paraphrase is a translating of the author's ideas in your own words. If you change some words from a sentence and you are thinking I am getting paraphrase, so it is not a legal way of paraphrasing. The student should change totally formation of the sentence as well as the words

\section{1: Major Mistakes in paraphrase}

There are eight main mistakes which are done by students in paraphrase, 1: Not deeply reading the ideas of authors, 2: adding a lot of as it is, 3: not adding key points, 4: adding belief, 5: concise rather than paraphrase, 6 using unsuitable words in paraphrase, 7: giving a lot of detail or closing idea, 8: and not saving the record.

\section{Plagiarism in writing}

Plagiarism has two categories first, copy data from other researcher's work and paste into your research paper. This type of data undoubtedly identities of plagiarism so, in the first papers of graduate-level students this type of mistakes are frequent and the other one category of plagiarism is minor changing in the words. According to Ozturk (2011) if we want to write good paraphrase, we need to understand the ideas of an author not just changing the synonyms of the words. Faulty understanding creates substandard paraphrasing. E. Powers 2015) mentioned that if the students are writing in the English language and English is not their native language, so there are a lot of problems in front of them while writing the paraphrase and student have not full command on that language and they become nervous 
and copy the data of previous researchers and paste it in their research paper to keep away from the grammar mistakes and finally, their research paper falls into plagiarism.

According to Ozturk (2011) those students who are writing their research paper often raise questions about plagiarism, how many words we need to change in a sentence to avoid the plagiarism, the answer is that there is no great words are phrase to add in a sentence to make the idea your own and real word needs real opinions.

The great and chief principle to avoid the plagiarism is giving the references at the end of the research paper, you need to write the last name author, publish year and the title of the research paper. The most important thing to discuss is the most students do not check their papers after completing it. There are lots of ways to check plagiarism such as a Quetext and WriteChecker, before submitting your paper to your teacher in order to check plagiarism, don't miss to first check plagiarism yourself.

\section{Second Language Problem}

Öztürk (2011), Singh (2015) they have similar opinion that the major thing behind the research paper is to develop the self-motivation in the graduate-level students. The research paper writing is a vital role for graduate-level students. The literature review is not difficult to write but two parts of the research paper is difficult first is an introduction and second is discussion because in literature review, we just take the ideas for our research paper but in the introduction and discussions we analyze the data, but that the language we are using, if it will be the second language (not in the mother tongue) so, it creates difficulty in writing. The fifty percent students of second language having problems in writing research papers but some students are skillful in vocabulary but they are weak in using right words in a research paper. When we write a research paper in the second language it is very difficult. The mostly student covert data from their mother tongue to second language 
(English) in which they are writing the research paper. It creates a lot of grammar mistakes and not provides clear ideas of authors. If the student will choose the topic, which is well known to them and cultural, it will solve their second language problem. The great role in writing any research paper is good guider. So, students need a good guide in writing their first research paper.

Chien, 2015 Nadia 2014, they have similar opinion that the students who are writing a research paper in second language, they have some kind of problems lack of knowledge and vocabulary. They cannot use good words to write their ideas and thoughts, therefore sometimes they have good ideas and thoughts but they have not good words to express these ideas in appropriate vocabulary, grammar and syntax. The main issue for the second language student is tense, articles and propositions. They cannot create cohesion and coherence in their work.

The students who are actually ESL, do not know the collocation and connotation meanings, therefore they have the problem of vocabulary. (Chien, 2015, Nadia 2014)) Similar opinion that second language students are not being motivated, they only read books to appear in exams. Because of this type thinking they have no interest in the study. There are lots of reasons behind this, why students have no interest in reading and writing, a lot of work to do, uninterested subjects, domestic problems and financial problems (some students are the only breadwinner in family).

Problems in choosing a topic

Kallestinova (2011) argued that the act of choosing a research topic for graduate level students, especially in choosing the first time, the students will not choose the topic correctly, they choose the topic without knowing the problems of that topic in details, If we know about the problems related to the chosen topic, we cannot write a good research paper and good 
literature review. However, the students of the graduate level who are writing their first research paper they choose an irrelevant topic, they choose the topic in which they have no interest and have no knowledge about the problems of the chosen topic.

Kallestinova (2011) argued that the topic of your research paper should show a problem, and this problem should be specific that is not shown in any other academic literature, this problem has to show in your introduction and then explain your motive and this motive should be a question. It is very difficult to choose the topic in writing the first research paper and main thing in the research paper is to find problems of the research topic which you will solve or introduce in that paper and it is a very difficult part of the paper. There are the main three things which are very important for students while choosing the research topic, B. Mennecke, Townsend Iowa State University (2012)

1. The Topic should be appropriate for research.

2. Interest in choosing a topic.

3. Don't choose a topic under any force (Pressure).

The starting point of the research paper According to Kallestinova (2011) the Student, who is writing their research paper first time it's hard to understand the starting point of a paper. We know all, the position of the abstract at the top, but we cannot write the abstract very first because first of all, we have to prepare a literature review because if we write the abstract in starting we are unable to write concise and lucid abstract. While preparing the literature review, we have to write the references at the same time, on the separate page, while borrowing the ideas, if we shall not do this we shall forget that, from where we borrowed these ideas related to our topic, it's easy for those students who are writing their research paper first time.

Kallestinova (2011) declared that the major problems faced by students in writing the research paper: Topic selection problem, problem in paraphrase, second language problem, 
literature review, plagiarism and format. The act of choosing a research topic for graduatelevel students, especially in choosing the first time, the students will not choose the topic correctly, they choose the topic without knowing the problems of that topic in details, If we know about the problems related to the chosen topic, we cannot write a good research paper and good literature review. We know all, the position of the abstract at the top, but we cannot write the abstract very first because first of all, we have to prepare a literature review because if we write the abstract in starting we are unable to write concise and lucid abstract. It is the general view about the students, and the criticism of the research assessors, it's hard to write good literature review for beginner researchers. Your literature review should have the ability to attract the readers, and there are some great contributions in your research paper on the topic. The common mistakes in writing the literature review. Firstly, using personal opinions and emotions, secondly, when you are giving the reference of any author use only the last name and year of study, some of the students use ULRs links. On the stage of graduation, it's time for the student to search out new things, using their own abilities, especially in research writing (Colwell 2011). This stage is to make student for developing their conceptual study, but students face problems in paraphrase. There are eight main mistakes which are done by students in paraphrase, 1: Not deeply reading the ideas of authors, 2: adding a lot of as it is, 3 : not adding key points, 4: adding belief, 5: concise rather than paraphrase, 6 using unsuitable words in paraphrase, 7: giving a lot of detail or closing idea, 8: and not saving the record. The students who are writing their research paper often raise questions about plagiarism. There is no great words are phrase to add in a sentence to make the idea your own, and realword needs real opinions The great and chief principle to avoid the plagiarism is giving the references at the end of the research paper, you need to write the last name author, publish year and the title of the research. There is another problem faced by students in writing research paper is second language problem. The fifty percent students of second language 
having problems in writing research papers but some students are skillful in vocabulary, but they are weak in using the right words in a research paper

\section{Methodology}

The major focus of the Methodology is to describe research methods which were used in data collection. I explain the research questions, objective, population and sampling.

Research questions

1: What are the problems for students in writing the first research paper in a second language?

a. How to write a good research paper?

\section{Objectives}

My research paper focuses on the problems which are faced by students in writing the first research paper, especially to those students who are writing in the second language Data presentation

This table is presenting the percentage of the problems of the research paper which they have faced while writing the research paper.

\begin{tabular}{|l|l|l|}
\hline Problems Faced in & Percentage & \multicolumn{1}{|c|}{ Remarks } \\
\hline Plagiarism & $70 \%$ & Students often raise the question, how to avoid the \\
plagiarism?
\end{tabular}




\begin{tabular}{|l|l|l|} 
Not interested & $60 \%$ & Students choose topic by other suggestions \\
\hline paper & & Adding the URLs links are against the rule \\
\hline Author's name & $50 \%$ & Students use the full name of the author in \\
\hline Synonyms & & references \\
\hline Unfamiliar with & $10 \%$ & Only change the synonym in order to avoid the \\
format & $30 \%$ & plagiarism \\
\hline Literature review & $30 \%$ & Not clearly familiar with format and process of \\
& & research \\
\hline Need of guidance & $70 \%$ & They write in the sampling test "We were in lack \\
\hline
\end{tabular}

Population and sample

The population of my study is the students who are writing the research paper first time and in second language either they are getting their Bachelor of master study. There were a hundred students (sample) from GC University hundred students (sample) from Punjab University who are writing their first research paper in the second language (English)

\section{Data Collection Procedure}

I have collected data from two hundred students and from two different universities for investigation in a practical way. I have collected them with the help of lecturers especially 
in GC University with the help of young researcher Sumaira Akhtar Hussain, who have the stormy knowledge about the research methods .before the taking test which I have organize I told to all the participants (sample) that this not ordinary test this is for the research purpose, and it will be kept for record. So they got test very honestly, I gave a blank page also to write down their problems in writing the first research paper in the second language. Actually my major test full with problems of research, but gave a blank page also because maybe they have some problems which researcher not know but there were very few students who write down which are actually indirectly in test. In the appendix section, I gave a picture of my test that is held in GC University Faisalabad.

\section{Data Analysis}

The data which I have collected is presented in the table by using Microsoft Office. I preferred the table in order to show the frequency of problems. I did not prefer the graphs in Microsoft excel.

Finding

In order to prove the research question, I have collected the data in a test form held in two different universities (GC University and Punjab University)

1. The test full with problems of research

2. A blank page to write down the problems which they faced in writing the research paper first time.

Students pointed out problems in the "Yes and No" test which they faced and also write down some problems in which they faced the first time in a research paper. In my appendix section, I have pasted one test page. Students have shown that they have problems in choosing a topic, problem about the format, how to get a literature review? 
Even some of the students do not know about what literature review is. They have problem in writing an abstract, and in major problem is methodology section.

\section{Discussion and Conclusion}

The major purpose of this study is to show the problems of the students which they have faced in writing the first research paper and also the solution to that problem. The data were collected from two different universities (Punjab University and GC University Faisalabad). According to the test performance of the students which has no knowledge about the basic things of the research, for example, the format of a research paper, how to start? How to give the end? How can get the literature review? Some students start their research paper from the abstract. Students have shown the problems of plagiarism, even one student of M.A English says: "I cannot solve the problem of plagiarism and I could not find out the much relevant data" students add the URLs links in the paper which is also against the rule of a research paper. Some students just use the synonyms while borrowing the ideas of Authors in order to avoid the plagiarism, the can solve the problems of the plagiarism but their material could not about to show the real idea which researcher want to convey. Fifty percent of students use the whole name of authors in order to give the references which are against the rule of the APA research format

Thirty percent students did not start their paper from the literature review. The very common and major problem of the research is writing the research in the second language and eighty percent students fall in this problem. By summing up my case I will say that some of the students who appeared in my test, they have shared with me that they faced these problems and commit these mistakes, after writing a first research paper they become familiar about all these things which they faced. The purpose of a researcher is not only showing the problems of research but to give the solution of these problems because beginner will not 
become hopeless that they are not able to write the paper. It is the duty of the teachers to guide the students for this type of academic work. Some of the students are very intelligent but they need just guidance. They have the ability to write this type of academic work but they cannot do because of guidance. 


\section{References}

Colwell AC 2011-242: Writing Challenges for Graduate Students in Engineering and Technology, Purdue University, Calumet (Tech)

Yulia 2012 Students' Problems in Writing Paraphrases in Research Paper Writing Class Chien, 2015, National Taipei University of Business, Taiwan, Graduate Students' Perceptions of the Problems in Writing Research Articles in English in Higher Education: A Taiwan-based Study

Nadia (2014) Second Language Writing and Culture: Issues and Challenges from the Saudi Learners' Perspective

Laramee, How to Write a Visualization Research Paper: A Starting Point Kallestinova (2011), How to write your first research paper.

Mei-Ching Ho, 2013 Taipei Municipal University of Education, Taiwan

The difficulties in disciplinary research writing: A case study of the first-year graduate students in Taiwan

Ozturk (2011) M.S., Department of Curriculum and Instruction, Çapa-Aydın, An assessment of academic writing needs of graduate students

Luse Iowa State University B. Mennecke Iowa State University, Townsend Iowa State University (2012) Selecting a Research Topic: A Framework for Doctoral Students Singh, (2015), PhD School of Languages, Literacies, and Translation Universiti Sains Malaysia (Malaysia), International Graduate Students' Academic Writing Practices in Malaysia: Challenges and Solutions

E. Powers (2015) the First Year of Graduate Study: Documenting Challenges and Informing Ways to Reduce Attrition 